(2) OPEN ACCESS

${ }^{1}$ Division of Infection, Immunity and Respiratory Medicine, School of Biological Sciences, Faculty of Biology, Medicine and Health, The University of Manchester, Manchester, UK ${ }^{2}$ Manchester Academic Health Science Centre and NIHR Manchester Biomedical Research Centre, Manchester University NHS Foundation Trust, Manchester, UK

\section{Correspondence to} Dr Hannah Jane Durrington, School of Biological Sciences, University of Manchester, Manchester M13 9PT, UK; hannah.durrington@ manchester.ac.uk

Received 19 October 2020 Revised 18 December 2020 Accepted 31 December 2020 Published Online First 27 January 2021

\title{
Asthma diagnosis: into the fourth dimension
}

\author{
Ran Wang (지, 1,2 Clare S Murray, ${ }^{1,2}$ Stephen J Fowler 다, 1,2 Angela Simpson, ${ }^{1,2}$ \\ Hannah Jane Durrington (1) ${ }^{1,2}$
}

\section{ABSTRACT}

Asthma is the most common chronic respiratory disease in the UK; however, the misdiagnosis rate is substantial. The lack of consistency in national guidelines and the paucity of data on the performance of diagnostic algorithms compound the challenges in asthma diagnosis. Asthma is a highly rhythmic disease, characterised by diurnal variability in clinical symptoms and pathogenesis. Asthma also varies day to day, seasonally and from year to year. As much as it is a hallmark for asthma, this variability also poses significant challenges to asthma diagnosis. Almost all established asthma diagnostic tools demonstrate diurnal variation, yet few are performed with standardised timing of measurements. The dichotomous interpretation of diagnostic outcomes using fixed cut-off values may further limit the accuracy of the tests, particularly when diurnal variability straddles cut-off values within a day, and careful interpretation beyond the 'positive' and 'negative' outcome is needed. The day-to-day and more long-term variations are less predictable and it is unclear whether performing asthma diagnostic tests during asymptomatic periods may influence diagnostic sensitivities. With the evolution of asthma diagnostic tools, home monitoring and digital apps, novel strategies are needed to bridge these gaps in knowledge, and circadian variability should be considered during the standardisation process. This review summarises the biological mechanisms of circadian rhythms in asthma and highlights novel data on the significance of time (the fourth dimension) in asthma diagnosis.

\section{INTRODUCTION}

Asthma is the most common chronic respiratory disease worldwide affecting 339 million people. ${ }^{1}$ It drives significant morbidity and mortality and poses a substantial health-economic burden. ${ }^{12}$ The UK has one of the highest asthma prevalence rates in Europe. ${ }^{3}$ Prevalence rates are based on accurate diagnosis; however, asthma is both overdiagnosed and underdiagnosed at the global level. ${ }^{4}$ In up to one-third of asthma patients, treatment can be safely withdrawn, ${ }^{5}$ raising concerns over significant misdiagnosis and overtreatment. ${ }^{13}$ In population-based studies, between $19 \%$ and $73 \%$ of adults and children who have symptoms and objective evidence in keeping with asthma have never been formally diagnosed, indicating considerable underdiagnosis. ${ }^{4-13}$ Misdiagnosing other conditions as asthma may cause harm to patients, and the inappropriate use of asthma treatment is associated with unnecessary side effects and cost, without any clinical benefit. ${ }^{1415}$ Failing to diagnose or treat asthma results in poor disease outcome and has important implications in the effective use of healthcare resources, but why is the misdiagnosis rate so high?

\section{Current challenges in asthma diagnosis}

Asthma is a heterogeneous clinical syndrome. While we now begin to understand the mechanisms driving some of the asthma phenotypes and endotypes, our knowledge remains limited, impeding accurate asthma definition and diagnosis. In spite of this complexity, the clinical features of asthma include (some or all of) reversible airflow obstruction, airway inflammation and bronchial hyperresponsiveness (BHR). ${ }^{18}$ All the currently available diagnostic tests are aimed at demonstrating one or more of these features. Peak expiratory flow (PEF), lung function and reversibility tests demonstrate airflow obstruction and variability, bronchoprovocation challenges examine BHR. $\mathrm{Fe}_{\mathrm{NO}}$, allergic sensitisation tests (skin prick test and immunoglobulin E (IgE)) and serum/sputum eosinophil counts are inflammatory biomarkers. In addition to clinical symptoms, an asthma diagnosis should be supported by objective evidence of variable airflow obstruction or inflammation, yet there is no single 'gold-standard' test. Adding to the challenge, national clinical guidelines have published somewhat conflicting recommendations, causing much concern among healthcare professionals. ${ }^{19}$ In a population-based birth cohort study, the asthma diagnostic algorithm for children recommended by the National Institute for Health and Care Excellence (NICE) was applied to 772 children. Strikingly, in this population, only $3 \%$ of children with current asthma had $\mathrm{FEV}_{1}$ to $\mathrm{FVC}$ ratio $\left(\mathrm{FEV}_{1}: \mathrm{FVC}\right)$ of less than $70 \% .{ }^{20}$ Bronchodilator reversibility tests (BDR) and $\mathrm{Fe}_{\mathrm{NO}}$ also demonstrated poor diagnostic accuracy using the recommended cut-off values. This raises concerns over the potential for delayed diagnosis in children or misdiagnosis; the comprehensive review of the literature that accompanied this guidance clearly demonstrated the paucity of evidence for the use of spirometry and bronchodilator reversibility in children. ${ }^{2021}$

Acknowledging that asthma is an umbrella term covering this heterogeneity, in 2015, Global Initiative for Asthma simplified their asthma definition to aid diagnosis in clinical practice. $^{22}$ This new definition highlights the cardinal features of variability in asthma: 'a history of respiratory symptoms such as wheeze, shortness of breath, chest tightness and cough that vary over time and in intensity" and "variable expiratory airflow limitation'. ${ }^{22}$ Despite this, the diagnostic guidelines continue to predominantly rely on using fixed and arbitrary cut-off values in the interpretation of tests, with little emphasis on the timing of measurements disease outcomes and excessive mortality. ${ }^{16} 17$ Accurate asthma diagnosis is pivotal in achieving good

To cite: Wang R, Murray CS, Fowler SJ, et al. Tho 
and how this may affect diagnostic accuracy. ${ }^{21} 23$ In this review, we will provide evidence that virtually all asthma diagnostic tests demonstrate diurnal and longer term variation; we will show how variability and timing impact asthma diagnosis and management. We provide an overview of the biological clock mechanism and highlight areas for future research.

\section{ASTHMA VARIABILITY: THE FOURTH DIMENSION: TIME Diurnal variability}

Asthma is a respiratory disease that demonstrates strong diurnal rhythmicity, typically with worsening symptoms overnight or early in the morning. ${ }^{24}$ Nocturnal symptoms affect $74 \%$ asthma patients leading to awakening at night at least once a week. ${ }^{24}$ Up to $80 \%$ of fatal asthma attacks in hospitalised patients occur overnight/early morning. ${ }^{25}{ }^{26}$ Excessive diurnal variations in symptoms and airflow obstruction are associated with disease severity and risk of death. ${ }^{24} 25$ A number of studies have consistently demonstrated that airway inflammation and airflow obstruction peak at 04:00. ${ }^{27-32}$ In patients with asthma, night-time PEF and $\mathrm{FEV}_{1}$ are reduced, and airway inflammation increased compared with daytime. ${ }^{27} 2831$ Moreover, patients with large overnight decrements in PEF also have increased airflow obstruction and BHR during the day. ${ }^{27}$ The amplitude of PEF diurnal variability can increase up to fourfold during unstable asthma compared with a symptom-free period, ${ }^{32}$ indicating that nocturnal dips in lung function are an important objective marker for disease control. During the development and validation of the Asthma Control Questionnaire, 'awoken at night by symptoms' was rated as the most important subjective marker for assessing adequacy of asthma control. ${ }^{33}$

\section{The biological clock in asthma}

Mechanisms of biological timing

The word 'circadian' comes from the Latin 'circa', meaning 'about', and 'dies', meaning 'day'. ${ }^{34}$ Circadian rhythms, driven by the 24-hour cycle of Earth's rotation, are generated by a molecular clock expressed in virtually all cells. The cellular circadian molecular clock consists of a positive arm-CLOCK (Circadian Locomotor Output Cycles Kaput) and BMAL1 (Brain and Muscle ARNT-Like 1), which interacts in the cytoplasm to form a complex (CLOCK:BMAL1) and activates the transcription of genes containing 'E-Box'. 3536 The CLOCK:BMAL1 complex drives the transcription of two inhibitory arms-PER/CRY (period gene: PER1, PER2 and PER3/cryptochrome gene: CRY1 and CRY2) and REV-ERB $\alpha / R E V-E R B \beta(\mathrm{Nr} 1 \mathrm{~d} 1 / \mathrm{Nr} 1 \mathrm{~d} 2$; nuclear receptor subfamily 1 , group $\mathrm{D}$, members 1 and 2), which feedback to inhibit BMAL1:CLOCK heterodimer transactivation function $^{35} 37$ (figure 1). The circadian clock powerfully regulates the oscillating rhythm of thousands of genes, proteins and metabolic processes throughout the body, thereby controlling biochemistry and physiology, including immune responses and inflammation. 35363839

While the cellular clocks express circadian oscillations when in isolation, complex and intimate interplay exists between the clocks and metabolic pathways at both local and systemic levels. A central clock in the suprachiasmatic nucleus of the brain, which is sensitive to light stimulation through the retina, synchronises peripheral tissue clocks via neural and humoral mediators. However, misalignment can occur (such as through chronic shift work, jet lag or disrupted lighting schedules) and negatively impact physiology and health. ${ }^{40-42}$

\section{The circadian clock and asthma}

The lungs contains its own autonomous peripheral clock mechanism, which is located in the bronchiolar epithelial cells. ${ }^{43}$ Many growth factor ligands, receptors, inflammatory molecules and airway glands, which are involved in the regulation and homeostasis of the lungs, show circadian influences. ${ }^{44-46}$ In particular, REV-ERB $\alpha$ plays a key role as a repressor of pulmonary inflammation. ${ }^{47}$

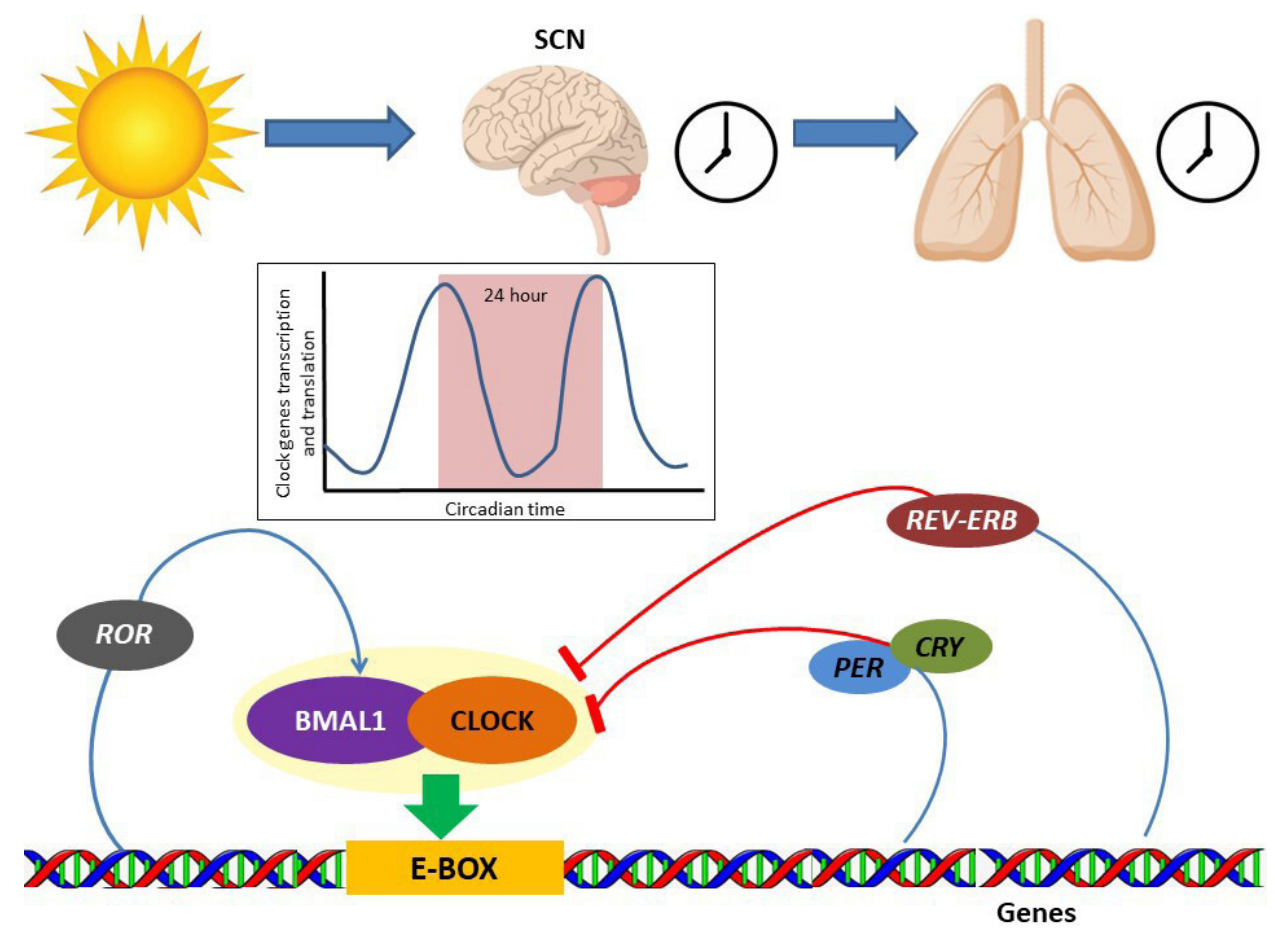

Figure 1 Schematic demonstration of biological clock network. BMAL1, Brain and Muscle ARNT-Like 1; CLOCK, Circadian Locomotor Output Cycles Kaput; CRY, cryptochrome gene; PER, period gene; ROR, RAR-related orphan receptor; SCN, suprachiasmatic nucleus. 
The role of circadian disruption in the pathophysiology of respiratory disease is complex. Environmental stressors such as jet lag, shift work and infections can result in circadian disruption, which in turn alter downstream clock-dependent physiological and immune responses. ${ }^{48}$ In murine studies, deletion of Bmal1 gene and circadian disruption by jet lag exacerbate acute viral bronchiolitis caused by influenza A and Sendai viruses. ${ }^{49}$ In Bmal1 knockout mice, extensive asthma-like airway changes, including increased airway resistance and mucus production, were observed after viral infection. ${ }^{49}$ In ovalbumin-induced allergic asthma model, deletion of Bmal1 in myeloid cells markedly increased lung inflammation, eosinophilia and interleukin $5,{ }^{50}$ suggesting it is a negative regulator. Interestingly, BMAL1 expression is lowest at night, potentially explaining increased nocturnal airway inflammation in asthma. Recently, using the house dust mite mouse model for allergic airways disease, and an in vitro precision cut lung slice model, we identified a pathway linking the core cellular clock, through REV-ERB $\alpha$ to airway reactivity, smooth muscle tone and airway narrowing. ${ }^{51}$ The time-of-day effects in airway hyper-responsiveness following allergen challenge were ablated in REV-ERB $\alpha$-deficient mice, as was rhythmic expression of key muscarinic receptor sub-classes, mediating cholinergic smooth-muscle responses. Intriguingly, the loss of clock gene expression, including REV-ERB $\alpha$, in the lung also appears to be a feature in patients with asthma compared with time-matched controls. ${ }^{49}$ In addition, children with respiratory syncytial virus bronchiolitis and persistent wheeze also demonstrated deficient BMAL1 expression in nasal washings. ${ }^{49}$

Using cross-sectional data from $>280000$ individuals from the UK Biobank, Maidstone et al demonstrated that permanent night shift workers had higher likelihood of acquiring asthma and worsened severity compared with day workers. This was following adjustment of major confounding factors, including social deprivation, occupational risks for asthma and smoking, indicating that circadian misalignment due to imbalance between the internal clock and the environment (external light-dark cycle) may impact on asthma acquisition and severity. ${ }^{41}$

In the context of allergic diseases, mast cell, basophil and eosinophil biology are all under circadian regulation. ${ }^{285253}$ The expression of high affinity $\mathrm{IgE}$ receptor (FceRI) in mast cells is under clock control and the stimulation of FceRI at different time points induces rhythmic production of cytokines in vitro. ${ }^{54}$ Basophil degranulation in response to $\mathrm{IgE}$ ligation demonstrates clear circadian rhythm in patients with allergic asthma, but not in controls. ${ }^{52}$ This rhythmic variation in basophil response is in acrophase with circadian variability of PEF in asthma ${ }^{52}$ (table 1).
Diurnal variability in asthma diagnostics

In making a diagnosis of asthma based solely on variability in symptoms, it is often difficult to differentiate asthma from 'asthma-like' illnesses and other small airway diseases such as COPD. ${ }^{2155} 56$ Self-reported diurnal symptoms alone poorly predict asthma with low sensitivity and specificity. ${ }^{21}$ Up to $80 \%$ of patients with COPD also self-report night-time or early morning symptoms and $90 \%$ showed variability in symptoms over a week. ${ }^{5657}$

\section{Airflow limitation}

The measurement of diurnal variation in airway calibre in asthma is a key component of the diagnostic process. ${ }^{23}$ However, it is paramount to understand that diurnal variation is not an 'all' or 'nothing' phenomenon that is exclusively observed in asthma. In fact, circadian rhythm is an inherent biological timing system present in all light-sensitive forms of life. ${ }^{35}$ Healthy individuals exhibit variability in lung physiology over 24-hour period, but in patients with asthma this response is exaggerated. ${ }^{58-60}$ For example, a mean circadian variation in $\mathrm{FEV}_{1}$ of $70 \mathrm{~mL}$ is present in healthy individuals, independent of environment and posture ${ }^{58}$ but in patients with mild to moderate asthma this amplitude may be more than doubled. ${ }^{29}$

Currently, PEF monitoring is the only diagnostic test used to demonstrate diurnal variability in asthma. Reliable demonstration of diurnal variation in PEF requires frequent measurement to minimise the missed variations between readings. In particular, underestimation of diurnal variation becomes increasingly likely if less than four evenly spaced out PEF readings are taken over 24 hours. ${ }^{6162}$ The commonly used twice-daily readings may underestimate PEF variability by up to $15 \%$ and pick up only $20 \%-45 \%$ of the true diurnal variation. ${ }^{61}{ }^{62}$ Errors in the timing of recording PEF will also result in missed peaks and troughs. ${ }^{60}$ However, increased frequency and stringent timing of daily readings are likely to result in reduced test completion rate. ${ }^{6063}$

\section{Bronchodilator responses and bronchial provocation challenges}

The diurnal variation in bronchodilator reversibility can be significant even in well-controlled and fully treated asthmatics. Sly and Landau demonstrated that more than half of stable asthmatic children had diurnal variations in BDR.$^{64}$ The peak of bronchodilator responses occurred between 02:00 and 04:00, with greater bronchodilation on waking in the morning compared with $16: 00$ (by $44 \mathrm{~L} / \mathrm{min}$ ). Interestingly, bronchodilation in the evening was also greater than in the afternoon, suggesting that

\begin{tabular}{ll}
\hline Table 1 Glossary & \\
\hline Amplitude & The maximum variation measured from mean \\
\hline Acrophase & Phase angle corresponding to the peak value of the rhythm \\
\hline Biological (peripheral) clock & Self-sustained circadian oscillation in absence of external periodic input \\
\hline Central (master) clock & The suprachiasmatic nucleus located in the basal hypothalamus of the brain, receiving external information via the retina \\
\hline Chronobiology & Study that examines timing processes or biological rhythms \\
\hline Chronotype & $\begin{array}{l}\text { The propensity for the individual to sleep at a particular time during a 24-hour period; it can be broadly categorised into three groups: (1) morning-type (wake up } \\
\text { early and sleep early, peak of physical and mental activity during early part of the day); (2) evening-type (wake up late and sleep late, with peak physical and mental } \\
\text { activity during end part of the day) and (3) neither }\end{array}$ \\
\hline Chronotherapy & Synchronisation of drug concentration to rhythms in disease activity \\
\hline Circadian rhythm & Biological processes that display oscillation over 24-hour periodicity \\
\hline Diurnal variation & Variation during the day between dawn and dusk \\
\hline
\end{tabular}


minimal BDR in PEF occur in the afternoon, coincident with least airway narrowing and airway inflammation. ${ }^{28} 65$

Direct bronchial provocation challenges performed overnight have more profound effects than during the day ${ }^{66-68}$ For example, both methacholine and histamine challenges demonstrate a twofold-threefold difference in provocation concentrations required to elicit $20 \%$ drop in $\mathrm{FEV}_{1}\left(\mathrm{PC}_{20}\right)$ at different times of day in mild asthmatics, with the maximal BHR occurring between 03:00 and 05:00. ${ }^{64} 6768$ Consistent with this, Martin and colleagues also reported significantly increased BHR at 04:00, and even normal saline inhalation at this time triggered $>20 \%$ fall in $\mathrm{FEV}_{1}{ }^{27}$ However, exercise challenge results in greater hyper-responsiveness in the afternoon (18:00) compared with the morning (07:00). ${ }^{69}$ Similarly, hyperventilation of cold air induced a maximal fall in $\mathrm{FEV}_{1}$ at 16:00, but this was halved at 04:00. ${ }^{64}$ The differences in the phases (where the peak and the trough occur) of BHR circadian changes with the nature of the challenge reflecting the different underlying mechanisms involved.

\section{Biomarkers}

Diurnal variation of $\mathrm{Fe}_{\mathrm{NO}}$ in asthma has been established in a number of studies. ${ }^{65707_{1}^{\circ}}$ Saito et al demonstrated diurnal variation in $\mathrm{Fe}_{\mathrm{NO}}$ in patients with asthma by using a domiciliary nitric oxide (NO) analyser and found the amplitude of $\mathrm{Fe}_{\mathrm{NO}}$ diurnal variation is more sensitive than $\mathrm{PEF}$ in predicting poor asthma control. ${ }^{70}$ In the paediatric population, diurnal variation in $\mathrm{Fe}_{\mathrm{NO}}$ was demonstrated with morning readings being $14 \%$ higher than the evening readings. ${ }^{71}$ Conversely, Kharitonov and colleagues failed to find diurnal variability of $\mathrm{Fe}_{\mathrm{NO}}$ in both adults and children with very mild asthma and normal lung function, ${ }^{72}$ although the study design and in particular the timing of the measurements (10:00-16:00) may have meant that the circadian peak and trough of $\mathrm{Fe}_{\mathrm{NO}}$ were missed. Georges et al investigated diurnal variation in exhaled $\mathrm{NO}$ by taking measurements at 04:00, 16:00 and 22:00 in asthma patients with and without nocturnal symptoms. $\mathrm{Fe}_{\mathrm{NO}}$ was the highest when taken at 16:00 compared with overnight in patients reporting nocturnal symptoms. ${ }^{73}$ Although this may suggest that nocturnal asthma represents a distinct circadian phenotype, it is also possible that nocturnal symptoms were reflective of poorer disease control; hence, a more pronounced diurnal variation was observed in this population. Recently, another study conducted by Wilkinson et al in patients with moderate atopic asthma reported diurnal variation in $\mathrm{Fe}_{\mathrm{NO}}$ when measured every 6 hours. ${ }^{65}$ The difference between the trough (overnight) and peak (10:00) of $\mathrm{Fe}_{\mathrm{NO}}$ was large $(12 \mathrm{ppb})$ even in stable asthmatics, ${ }^{65}$ and could be even larger in uncontrolled cases. ${ }^{70}$ Importantly, the intrasubject diurnal variations in $\mathrm{Fe}_{\mathrm{NO}}$ straddled the currently recommended fixed diagnostic cut-offs, and, therefore, may potentially impact on diagnostic accuracies. ${ }^{65}$

Airway eosinophilia also demonstrate diurnal variability. ${ }^{28303174}$ Eosinophil counts in the bronchoalveolar lavage at 04:00 are twofold-threefold higher than 16:00 in patients with asthma. ${ }^{30} 74$ Transbronchial biopsies in patients with nocturnal asthma had four times higher alveolar tissue eosinophils at 04:00 compared with 16:00. ${ }^{31}$ Durrington and colleagues found that patients with severe asthma attending morning clinics were twice as likely to have sputum eosinophilia compared with patients attending afternoon clinics. ${ }^{28}$ This variation was only observed in asthma and not in healthy controls. However, diurnal variation in blood eosinophils was present in both healthy and asthma. $^{28}$ Furthermore, circadian variation in total $\mathrm{IgE}$ levels have been previously documented in both non-allergic and allergic asthmatic children, with $\sim 30 \%$ variability observed with two diurnal peaks and one nocturnal trough. ${ }^{75}$ Exhaled volatile organic compounds (VOCs) are novel breath biomarkers. Some VOCs become rhythmic in asthma, ${ }^{65}$ highlighting the need for considering time-of-the-day effects during the standardisation and validation processes of novel asthma biomarkers.

The human biological clock is a remarkable built-in mechanism that is well integrated with the Earth's rotation and changes in light, temperature and other environmental factors. Therefore, the circadian amplitude of variation in asthma can be highly dynamic, interacting with changes in environmental and disease activities. $^{7076}$ Even in stable asthmatic children who have nearly outgrown asthma, significant differences in circadian amplitude of lung function have been observed between seasons, with the highest during winter months. ${ }^{77}$ Interestingly, this coincides with the seasonal variation of the lowest level of BMAL1 expression, ${ }^{78}$ but the causal relationship between the two is unclear. Circadian oscillation is predictable. Nevertheless, there is paucity of data to investigate whether diagnostic error caused by circadian variability can be adjusted by the time-of -day effect. Furthermore, interindividual differences in chronophenotypes of $\mathrm{FEV}_{1}$ phases exist in healthy volunteers, ${ }^{79}$ but whether these differences exist among asthma patients is unknown. It is also unclear if the same circadian patterns can be observed in all asthma phenotypes/endotypes. Ascertaining such chronophenotypes in asthma would be beneficial in delivering tailored diagnostic strategies in measuring diurnal variability. Notably, chronotypes (patients preferred pattern of sleep, see table 1) influence asthma risks and nocturnal symptoms, and may also impact on the diurnal variations and chronophenotypes in asthma. 41778081

\section{Day-to-day variability}

Day-to-day variability in asthma is less well studied than diurnal variability. Marked increase in BHR can occur within 24 hours after exposure to sensitizers and can resolve within a week. ${ }^{82}$ Significant day-to-day variability in airway resistance and reactance using forced oscillation technique have been demonstrated by Goldman and colleagues during a stable period of asthma. ${ }^{83}$ However, this was markedly increased through exacerbation periods and was linked with poor medication adherence and asthma control. ${ }^{84} 85 \mathrm{Fe}_{\mathrm{NO}}$ also exhibits between-day variability. ${ }^{70} 718687$ Ekroos et al investigated the short-term variability of $\mathrm{Fe}_{\mathrm{NO}}$ in healthy volunteers and patients with mild asthma at $10 \mathrm{~min}, 6$ hours and 24 hours, and found that the variation over 24 hours were higher compared with those of shorter time periods. ${ }^{87}$ Furthermore, the coefficient of variation in $\mathrm{Fe}_{\mathrm{NO}}$ over 24 hours was more than doubled in those who have asthma compared with healthy volunteers. Interestingly, even in symptomatic individuals who did not fulfil the functional criteria of asthma, the day-to-day variation was twice as high as healthy controls. ${ }^{87}$ In asthmatic children, the day-to-day variation of $\mathrm{Fe}_{\mathrm{NO}}$ over 2 weeks was even higher, with the coefficient of variance of between $36 \%$ and $40 \% .^{71}$ Saito et al demonstrated significantly increased day-to-day fluctuations in $\mathrm{Fe}_{\mathrm{NO}}$ in uncontrolled asthma compared with well-controlled asthma patients, suggesting these short-term variability of $\mathrm{Fe}_{\mathrm{NO}}$ could be a surrogate biomarker for disease control and predictor for risk of future exacerbations. ${ }^{70}$ However, unlike diurnal variability, the day-to-day variation is less predictable in individual patients in the diagnostic setting and its impact on diagnostic accuracies is unclear.

To overcome short-term between-day variations, Wong et al calculated the mean of daily airway resistance/reactance over a 
period of time. ${ }^{84}$ Similarly, the mean of $\mathrm{Fe}_{\mathrm{NO}}$ obtained over two consecutive days at the start and during treatment were used to reliably determine response to inhaled corticosteroids during the evaluation of $\mathrm{Fe}_{\mathrm{NO}}$ suppression test in severe asthma. ${ }^{88}$ However, these measures are costly and time consuming in clinical practice. As the diagnosis of asthma is commonly based on one-off testing, future research is needed to elucidate the implication of day-to-day variability on diagnostic accuracy.

\section{Longer term variability}

Asthma pathophysiology and disease activity can vary significantly over years. It is well known that remission of asthma in children is common during the second decade of life, but many relapse later on. ${ }^{89}$ Panhuysen et al followed up 181 patients between the ages of 13 years and 44 years with confirmed asthma, and retested for BHR, airflow obstruction and clinical symptoms 25 years later. Of these, 11\% were no longer considered to have asthma, ${ }^{90}$ suggesting adult patients may also 'outgrow' asthma. Even in patients with adult-onset asthma phenotype, one in six patients experiences remission within the first 5 years. ${ }^{91}$ Although milder disease has been associated with better long-term outcome, Ross et al has demonstrated that half of the children with severe asthma no longer had severe asthma at 3 -year follow-up, ${ }^{92}$ indicating there is a significant resolution rate even in the severe asthma population.

Variation in asthma control and pathophysiology can be observed over a shorter period of time. Peak flow variability, decrements in lung function and other biomarkers such as eosinophils may also increase during acute exacerbations and improve with recovery following treatment. ${ }^{93}$ Vahlkvist et al demonstrated more than threefold increase in $\mathrm{Fe}_{\mathrm{NO}}$ during the pollen season in birch pollen allergic mildly asthmatic children, without significant change in peak flow. ${ }^{94}$ Skiepko and colleagues measured $\mathrm{Fe}_{\mathrm{NO}} 3-5$ months before and during pollen season in patients with grass pollen allergic rhinitis and BHR. Strikingly, $\mathrm{Fe}_{\mathrm{NO}}$ more than doubled during pollen season, with markedly increased BHR to histamine (by more than 10-fold) when compared with pre-season. ${ }^{95}$ Notably, these seasonal differences straddled the fixed clinical cut-off values. Hence, allergen exposure or avoidance in sensitised individuals near the time of clinical assessment may affect diagnostic outcome. Furthermore, Selvanathan et al showed that in $20 \%$ of patients with asthma who had a negative methacholine challenge went onto have positive BHR following medication tapering. However, spontaneous variations in BHR also occurred during follow-up at 6 months and 12 months in $15 \%$ of patients irrespective of seasonal or medication changes. ${ }^{96}$
Even in the absence of changes in lung physiology, asthma treatment or symptom scores, considerable biological inflammatory changes have been observed in repeated endobronchial biopsies in stable asthmatics obtained 1 month apart. ${ }^{97}$ Sputum inflammatory phenotypes are unstable in children with asthma over 12 months, independent of asthma medications or disease control. ${ }^{98}$ Similarly, marked longitudinal instability in sputum cellularity, bronchodilator responses, biomarkers and lung function have been observed in adults within a year. ${ }^{99} 100$

Influencing factors such as lifestyle changes, infections, medication compliance, pollution and climate further impact on the natural history of asthma in an individual, making reliable asthma diagnosis based on a snapshot assessment challenging. Serial measurements and cautious interpretation of tests results by taking into account of these factors at the time of tests may be a valuable diagnostic strategy.

\section{THE FUTURE OF ASTHMA DIAGNOSIS Timing matters}

Variability in asthma diagnostic tests has been realised for more than 20 years, $30316466-6974$ and our ongoing work continues to support this. ${ }^{65} 70$ However, the current 'snapshot' diagnostic strategy remains inadequate in addressing this key issue.

The natural history of asthma is heterogeneous and complex, with continuous and dynamic diurnal, day-to-day and longer term variability (figure 2). In clinical settings, variability in the outcome of diagnostic tests is further compounded by variations in test techniques and reproducibility of the test itself. Knowing patients' disease timeline and symptom triggers, and integrating this knowledge with the timing of diagnostic tests may improve the accuracy of interpretation of test results. The recommended fixed cut-off points for diagnostic tests should never be used in the absence of detailed clinical history and the consideration of timing of the test. For example, a borderline lung function measured during an episode of assumed 'acute exacerbation' may give a very different diagnostic probability of asthma than if the test was performed during a stable and asymptomatic period. While achieving accurate asthma diagnosis based on a snapshot assessment at a random time point is ambitious, prompt reviewing and reassessment as the disease evolves, with appropriate retesting will probably improve diagnostic accuracies. Performing diagnostic tests when patients are more symptomatic may also enhance diagnostic efficiency than during asymptomatic periods. However, there is little evidence to support this.

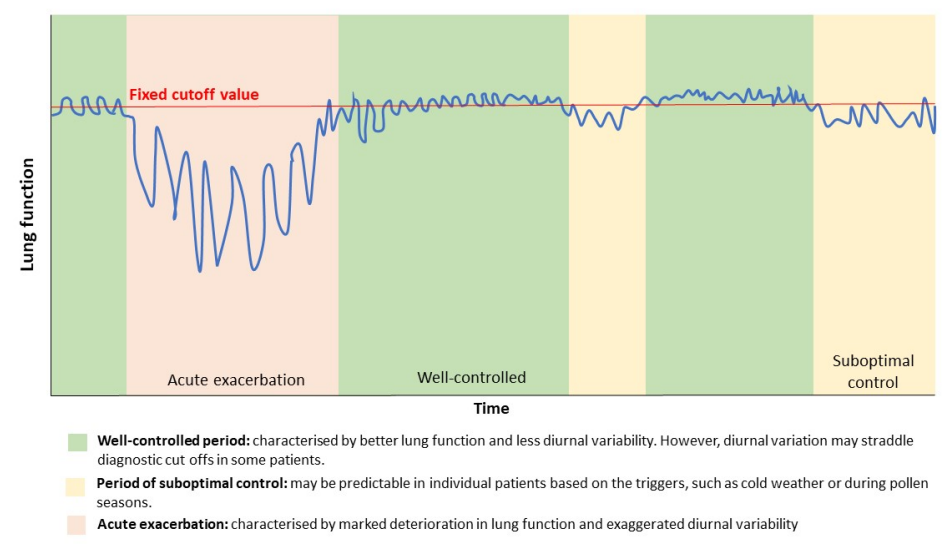

Figure 2 The timing of asthma diagnostic tests matters: a schematic diagram demonstrating variability of asthma with time. 
As asthma treatment is moving away from 'one-size fits all' approach towards more personalised strategies, perhaps, the paradigm of diagnostic approach should also be shifted away from complete reliance on dichotomous interpretation based on unified and fixed cut-offs from 'one-off' testing. Ascertaining circadian patterns of diagnostic tests in asthma and appropriate adjustment of the 'cut-off' values according to timing of measurements may improve asthma diagnosis in some patients. With the evolving face of asthma diagnostic strategies, novel tools are needed in order to bridge gaps in knowledge. It is important to consider the time-of-the-day effects during the validation and standardisation processes in patients with asthma.

\section{Moving beyond 'one-off' testing}

As the definition of asthma highlights the feature of 'variability', it may be that the focus should be on demonstrating variations in diagnostic measurements rather than the absolute values. The possibility of using home testing devices, accompanied by innovative apps, at the diagnostic stage will be valuable in capturing the day-to-day variabilities and allow taking measurements at the right time points for diurnal variations in asthma.

While home-based spirometry devices are commercially available, the role in asthma diagnosis remains unclear. Homebased $\mathrm{Fe}_{\mathrm{NO}}$ and forced oscillometry measurements appeared to be feasible in previous studies and demonstrated clear advantage over PEF in asthma monitoring, ${ }^{70} 8485$ but their usefulness in diagnostic settings needs to be urgently studied as the next step. Such studies in the evaluation of home-based testing will provide opportunities for repeated measurements during the day and night (over 24-hour period), through which rhythmicity can be determined. Importantly, careful chronotypical assessment of patients (using validated questionnaires ${ }^{101}{ }^{102}$ ) is mandatory in the accurate interpretation of chronobiological data. The patterns of any circadian rhythm function (including asthma symptoms and pathophysiological patterns) may vary largely between chronotypes (see definitions in table 1). Indeed, several studies have shown that phase shifts (phase advance or delay) between extreme chronotypes (the morning and evening types) range from 2 hours to 12 hours, depending on the biological and behavioural parameters measured. ${ }^{103}$ This suggests that the timing of peak and trough in lung function and asthma biomarkers may also be very different with chronotype differences and should be appropriately stratified.

It is important to note that ascertaining the biological rhythm in asthma will not only benefit in home-based testing strategy, but will also 'personalise' the clinic-based diagnostic tests (including bronchial provocation challenges, airway eosinophilia assessment from induced sputum and blood biomarkers) by interpreting using time-adjusted and chronotype-adjusted values. It may be possible that the relative expression of core clock genes in blood (or tissue) samples can provide a 'biological time stamp' for the interpretation of 'one-off' testing, and this should be explored in future research.

As circadian rhythmicity is ubiquitous among all individuals, it is paramount to thoroughly characterise and define what constitutes an 'abnormally exaggerated' circadian pattern in lung function (and other diagnostic tests) as the first step. Therefore, the initial study should include patients with definite asthma, healthy volunteers and those with asthma-like conditions/symptoms (eg, COPD). Although it is expected that the amplitude/patterns of circadian rhythm to differ after chronotype stratification among the disease groups, a degree of overlap remains possible, in which case this should be carefully quantified and acknowledged. It is also noteworthy that the discriminative power should be rigorously investigated in asthma diagnosis (eg, prospective studies of symptomatic and treatment-naïve patients) before clinical implementation.

In addition to the measurement of diurnal/circadian variability in asthma, a home-based testing strategy also confers the advantage of capturing day-to-day and longer term variabilities, and provides opportunity for lung function and biomarker measurements at the time of exacerbations (such as following exposures to triggers). This is crucial in the diagnostic workup.

Close collaborations with industry will be mandatory in the future in driving the development of user friendly and costeffective devices for home-based testing that can be widely used in primary care (where $85 \%$ of asthma patients are diagnosed and managed ${ }^{104}$ ) and secondary care. With rapidly evolving technology and advances in data science, we are in a unique era where a personalised approach in asthma care can be possible through the integration of digital information (including sleep/ awake cycle measurements using technologies such as wrist actigraphy, ${ }^{105}$ the exposure of personal triggers through location, pollution, weather and temperature forecasting and timing of medication administration and test results into one system. The incorporation of chronobiology in asthma care can also provide opportunities to deliver tailored treatment according to the rhythmicity of disease (chronotherapy), which may result in better disease control with lower doses of medications. Home-based testing moves beyond our current 'one-off' testing strategy and opens a door to a new approach in asthma care. This approach not only has the potential to empower patients in managing this highly variable disease, but also provides opportunities in creating a better patient-clinician partnership.

Twitter Stephen J Fowler @Stephen」_Fowler and Hannah Jane Durrington @ durrington

Acknowledgements RW, CSM, SJF, AS and HJD are all supported by theNIHR Manchester Biomedical Research Centre.

Contributors RW, CSM, SJF, AS and HJD all contributed to the planning, conception, design, acquisition of data and writing of this article.

Funding The authors have not declared a specific grant for this research from any funding agency in the public, commercial or not-for-profit sectors.

Competing interests None declared.

Patient consent for publication Not required.

Provenance and peer review Not commissioned; externally peer reviewed.

Open access This is an open access article distributed in accordance with the Creative Commons Attribution Non Commercial (CC BY-NC 4.0) license, which permits others to distribute, remix, adapt, build upon this work non-commercially, and license their derivative works on different terms, provided the original work is properly cited, appropriate credit is given, any changes made indicated, and the use is non-commercial. See: http://creativecommons.org/licenses/by-nc/4.0/.

\section{ORCID iDs}

Ran Wang http://orcid.org/0000-0003-3324-969X

Stephen J Fowler http://orcid.org/0000-0002-4524-1663

Hannah Jane Durrington http://orcid.org/0000-0002-9990-9446

\section{REFERENCES}

1 World Health Organisation. Asthma. Available: https://www.who.int/en/news-room/ fact-sheets/detail/asthma. [Accessed 29 Sep 2020].

2 Nunes C, Pereira AM, Morais-Almeida M. Asthma costs and social impact. Asthma Res Pract 2017;3:1.

3 To T, Stanojevic S, Moores G, et al. Global asthma prevalence in adults: findings from the cross-sectional World health survey. BMC Public Health 2012;12:204.

4 Aaron SD, Boulet LP, Reddel HK, et al. Underdiagnosis and overdiagnosis of asthma. Am J Respir Crit Care Med 2018;198:1012-20.

5 Aaron SD, Vandemheen KL, FitzGerald JM, et al. Reevaluation of diagnosis in adults with Physician-Diagnosed asthma. JAMA 2017;317:269-79. 
6 van Schayck CP, van Der Heijden FM, van Den Boom G, et al. Underdiagnosis of asthma: is the doctor or the patient to blame? the DIMCA project. Thorax 2000;55:562-5.

7 Adams RJ, Wilson DH, Appleton S, et al. Underdiagnosed asthma in South Australia. Thorax 2003; 58:846-50.

8 Backer V, Harmsen L, Lund T, et al. A 3-year longitudinal study of asthma quality of life in undiagnosed and diagnosed asthma patients. Int J Tuberc Lung Dis 2007:11:463-9.

9 de Marco R, Cerveri I, Bugiani M, et al. An undetected burden of asthma in Italy: the relationship between clinical and epidemiological diagnosis of asthma. Eur Respir J 1998;11:599-605.

10 Siersted HC, Boldsen J, Hansen HS, et al. Population based study of risk factors for underdiagnosis of asthma in adolescence: Odense schoolchild study. BMJ 1998;316:651-5.

11 van Gent R, van Essen LEM, Rovers MM, et al. Quality of life in children with undiagnosed and diagnosed asthma. Eur J Pediatr 2007;166:843-8.

12 Enright PL, McClelland RL, Newman AB, et al. Underdiagnosis and undertreatment of asthma in the elderly. cardiovascular health study Research Group. Chest 1999:116:603-13.

13 Parameswaran K, Hildreth AJ, Chadha D, et al. Asthma in the elderly: underperceived, underdiagnosed and undertreated; a community survey. Respir Med 1998;92:573-7.

$14 \mathrm{Kim} \mathrm{MH}$, Rhee CK, Shim JS, et al. Inhaled corticosteroids in asthma and the risk of pneumonia. Allergy Asthma Immunol Res 2019;11:795-805.

15 Simons FE. Benefits and risks of inhaled glucocorticoids in children with persistent asthma. J Allergy Clin Immunol 1998;102:S77-84.

16 Amin S, Soliman M, Mclvor A, et al. Usage patterns of short-acting $\beta 2$-Agonists and inhaled corticosteroids in asthma: a targeted literature review. J Allergy Clin Immunol 2020;8:2556-64.

17 Anagnostou K, Harrison B, lles R, et al. Risk factors for childhood asthma deaths from the UK eastern region confidential enquiry 2001-2006. Prim Care Respir J 2012;21:71-7

18 Holgate ST. Innate and adaptive immune responses in asthma. Nat Med 2012;18:673-83.

19 Fowler SJ, O'Byrne PM, Buhl R, et al. Two pathways, one patient; UK asthma guidelines. Thorax 2018;73:797-8.

20 Murray C, Foden P, Lowe L, et al. Diagnosis of asthma in symptomatic children based on measures of lung function: an analysis of data from a population-based birth cohort study. Lancet Child Adolesc Health 2017;1:114-23.

21 The National Institute for Health and Care Excellence. Asthma. Available: https://cks. nice.org.uk/asthma\#! diagnosisSub [Accessed 29 Sep 2020].

22 Reddel HK, Bateman ED, Becker A, et al. A summary of the new GINA strategy: a roadmap to asthma control. Eur Respir J 2015;46:622-39.

23 SIGN. British thoracic society and Scottish Intercollegiate guidelines network SIGN158: British guideline on the management of asthma. Available: https://www. sign.ac.uk/assets/sign 158.pdf [Accessed 29 Sep 2020].

24 Turner-Warwick M. Nocturnal asthma: a study in general practice. J R Coll Gen Pract 1989;39:239-43.

25 Hetzel MR, Clark TJ, Branthwaite MA. Asthma: analysis of sudden deaths and ventilatory arrests in hospital. Br Med J 1977;1:808-11.

26 Cochrane GM, Clark JH. A survey of asthma mortality in patients between ages 35 and 64 in the greater London hospitals in 1971. Thorax 1975;30:300-5.

27 Martin RJ, Cicutto LC, Ballard RD. Factors related to the nocturnal worsening of asthma. Am Rev Respir Dis 1990;141:33-8.

28 Durrington HJ, Gioan-Tavernier GO, Maidstone RJ, et al. Time of day affects eosinophil biomarkers in asthma: implications for diagnosis and treatment. Am J Respir Crit Care Med 2018;198:1578-81.

29 Zhou D, Li H, Wang Y, et al. Quantitative characterization of circadian rhythm of pulmonary function in asthmatic patients treated with inhaled corticosteroids. $J$ Pharmacokinet Pharmacodyn 2015:42:391-9.

30 Martin RJ, Cicutto LC, Smith HR, et al. Airways inflammation in nocturnal asthma. Am Rev Respir Dis 1991:143:351-7.

31 Kraft M, Djukanovic R, Wilson S, et al. Alveolar tissue inflammation in asthma. Am J Respir Crit Care Med 1996;154:1505-10.

32 Burioka N, Suyama H, Sako T, et al. Circadian rhythm in peak expiratory flow: alteration with nocturnal asthma and theophylline chronotherapy. Chronobiol Int 2000;17:513-9.

33 Juniper EF, O'Byrne PM, Guyatt GH, et al. Development and validation of a questionnaire to measure asthma control. Eur Respir J 1999;14:902-7.

34 Nainwal N. Chronotherapeutics--a chronopharmaceutical approach to drug delivery in the treatment of asthma. J Control Release 2012:163:353-60.

35 Lowrey PL, Takahashi JS. Mammalian circadian biology: elucidating genome-wide levels of temporal organization. Annu Rev Genomics Hum Genet 2004;5:407-41.

36 Green CB, Takahashi JS, Bass J. The meter of metabolism. Cell 2008;134:728-42.

37 Mohawk JA, Green CB, Takahashi JS. Central and peripheral circadian clocks in mammals. Annu Rev Neurosci 2012:35:445-62.

38 Gibbs JE, Blaikley J, Beesley S, et al. The nuclear receptor Rev-erb $\alpha$ mediates circadian regulation of innate immunity through selective regulation of inflammatory cytokines. Proc Natl Acad Sci U S A 2012;109:582-7.
39 Narasimamurthy R, Hatori M, Nayak SK, et al. Circadian clock protein cryptochrome regulates the expression of proinflammatory cytokines. Proc Natl Acad Sci U S A 2012;109:12662-7.

40 Hadden H, Soldin SJ, Massaro D. Circadian disruption alters mouse lung clock gene expression and lung mechanics. J App/ Physio/ 2012;113:385-92.

41 Maidstone R, Turner J, Vetter C. Night shift work increases the risk of asthma. medRxiv 2020.

42 Mason IC, Qian J, Adler GK, et al. Impact of circadian disruption on glucose metabolism: implications for type 2 diabetes. Diabetologia 2020;63:462-72.

43 Gibbs JE, Beesley S, Plumb J, et al. Circadian timing in the lung; a specific role for bronchiolar epithelial cells. Endocrinology 2009;150:268-76.

44 Durrington HJ, Farrow SN, Loudon AS, et al. The circadian clock and asthma. Thorax 2014;69:90-2.

45 Sukumaran S, Jusko WJ, Dubois DC, et al. Light-Dark oscillations in the lung transcriptome: implications for lung homeostasis, repair, metabolism, disease, and drug action. J Appl Physiol 2011;110:1732-47.

46 Bando $\mathrm{H}$, Nishio T, van der Horst GTJ, et al. Vagal regulation of respiratory clocks in mice. J Neurosci 2007:27:4359-65.

47 Pariollaud M, Gibbs JE, Hopwood TW, et al. Circadian clock component Reverb $\alpha$ controls homeostatic regulation of pulmonary inflammation. J Clin Invest 2018:128:2281-96.

48 Sundar IK, Yao H, Sellix MT, et al. Circadian molecular clock in lung pathophysiology. Am J Physiol Lung Cell Mol Physiol 2015;309:L1056-75.

49 Ehlers A, Xie W, Agapov E, et al. Bmal1 links the circadian clock to viral airway pathology and asthma phenotypes. Mucosal Immunol 2018;11:97-111.

50 Zasłona Z, Case S, Early JO, et al. The circadian protein BMAL1 in myeloid cells is a negative regulator of allergic asthma. Am J Physiol Lung Cell Mol Physiol 2017;312:L855-60.

51 Durrington HJ, Krakowiak K, Meijer P, et al. Circadian asthma airway responses are gated by Rev-erbo. Eur Respir J 2020;56:1902407.

52 Spadaro G, Giurato G, Stellato C, et al. Basophil degranulation in response to $\mathrm{lg}$ E ligation is controlled by a distinctive circadian clock in asthma. Allergy 2020:75:158-68.

53 Christ P, Sowa AS, Froy 0 , et al. The circadian clock drives mast cell functions in allergic reactions. Front Immunol 2018;9:1526.

54 Wang X, Reece SP, Van Scott MR, et al. A circadian clock in murine bone marrowderived mast cells modulates IgE-dependent activation in vitro. Brain Behav Immun 2011:25:127-34

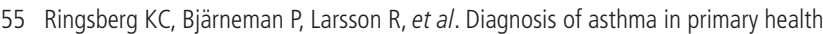
care: a pilot study. J Allergy 2014;2014:1-8.

56 Scichilone N, Antonelli Incalzi R, Blasi F, Nicola S, Raffaele Al, Francesco B, et al. Circadian rhythm of COPD symptoms in clinically based phenotypes. results from the STORICO Italian observational study. BMC Pulm Med 2019;19:171.

57 Miravitlles M, Izquierdo JL, Esquinas C, et al. The variability of respiratory symptoms and associated factors in COPD. Respir Med 2017;129:165-72.

58 Spengler CM, Shea SA. Endogenous circadian rhythm of pulmonary function in healthy humans. Am J Respir Crit Care Med 2000;162:1038-46.

59 Hetzel MR, Clark TJ. Comparison of normal and asthmatic circadian rhythms in peak expiratory flow rate. Thorax 1980;35:732-8.

60 Reddel $H$, Jenkins C, Woolcock A. Diurnal variability--time to change asthma guidelines? BMJ 1999;319:45-7.

61 Gannon PF, Newton DT, Pantin CF, et al. Effect of the number of peak expiratory flow readings per day on the estimation of diurnal variation. Thorax 1998:53:790-2

62 D'Alonzo GE, Steinijans VW, Keller A. Measurements of morning and evening airflow grossly underestimate the circadian variability of FEV1 and peak expiratory flow rate in asthma. Am J Respir Crit Care Med 1995;152:1097-9.

63 Côté J, Cartier A, Malo JL, et al. Compliance with peak expiratory flow monitoring in home management of asthma. Chest 1998;113:968-72.

64 Sly PD, Landau LI. Diurnal variation in bronchial responsiveness in asthmatic children. Pediatr Pulmonol 1986;2:344-52.

65 Wilkinson M, Maidstone R, Loudon A, et al. Circadian rhythm of exhaled biomarkers in health and asthma. Eur Respir J 2019;54. doi:10.1183/13993003.01068-2019. [Epub ahead of print: 17 Oct 2019].

66 Jarjour NN. Circadian variation in allergen and nonspecific bronchial responsiveness in asthma. Chronobiol Int 1999;16:631-9.

67 Bonnet $\mathrm{R}$, Jörres $\mathrm{R}$, Heitmann $\mathrm{U}$, et al. Circadian rhythm in airway responsiveness and airway tone in patients with mild asthma. J App/ Physiol 1991;71:1598-605.

68 van Aalderen WM, Postma DS, Koëter GH, et al. Circadian change in bronchial responsiveness and airflow obstruction in asthmatic children. Thorax 1989:44:803-7

69 Vianna EO, Boaventura LC, Terra-Filho J, et al. Morning-to-evening variation in exercise-induced bronchospasm. J Allergy Clin Immunol 2002;110:236-40

70 Saito J, Gibeon D, Macedo P, et al. Domiciliary diurnal variation of exhaled nitric oxide fraction for asthma control. Eur Respir J 2014;43:474-84.

71 Pijnenburg MW, Floor SE, Hop WC, et al. Daily ambulatory exhaled nitric oxide measurements in asthma. Pediatr Allergy Immunol 2006;17:189-93. 
72 Kharitonov SA, Gonio F, Kelly C, et al. Reproducibility of exhaled nitric oxide measurements in healthy and asthmatic adults and children. Eur Respir J 2003;21:433-8.

73 Georges G, Bartelson BB, Martin RJ, et al. Circadian variation in exhaled nitric oxide in nocturnal asthma. J Asthma 1999;36:467-73.

74 Mackay TW, Wallace WA, Howie SE, et al. Role of inflammation in nocturnal asthma. Thorax 1994;49:257-62.

75 Gaultier C, De Montis G, Reinberg A, et al. Circadian rhythm of serum total immunoglobin E (IgE) in asthmatic children. Biomed Pharmacother 1987;41:186-8.

76 Kondo S, Ito M. Seasonal variation in the circadian rhythm of pulmonary function in stable asthmatic children who have nearly outgrown their asthma. Chronobiol Int 1996;13:295-303.

77 Haldar P, Carsin A-E, Debnath S, et al. Individual circadian preference (chronotype) is associated with asthma and allergic symptoms among adolescents. ERJ Open Res 2020;6:00226-20.

78 Dopico XC, Evangelou M, Ferreira RC, et al. Widespread seasonal gene expression reveals annual differences in human immunity and physiology. Nat Commun 2015;6:7000

79 Goyal M, Goel A, Bhattacharya S, et al. Circadian variability in airways characteristics: a spirometric study. Chronobiol Int 2019;36:1550-7.

80 Merikanto I, Englund A, Kronholm E, et al. Evening chronotypes have the increased odds for bronchial asthma and nocturnal asthma. Chronobiol Int 2014;31:95-101.

81 Ferraz E, Borges MC, Vianna EO. Influence of nocturnal asthma on chronotype. J Asthma 2008;45:911-5.

82 Cockcroft DW, Mink JT. Isocyanate-induced asthma in an automobile spray painter. Can Med Assoc J 1979;121:602-4.

83 Goldman MD, Carter R, Klein R, et al. Within- and between-day variability of respiratory impedance, using impulse oscillometry in adolescent asthmatics. Pediatr Pulmonol 2002;34:312-9.

84 Wong A, Hardaker K, Field P, et al. Home-based forced oscillation technique day-to-day variability in pediatric asthma. Am J Respir Crit Care Med 2019;199:1156-60.

85 Robinson PD, Brown NJ, Turner M, et al. Increased day-to-day variability of forced oscillatory resistance in poorly controlled or persistent pediatric asthma. Chest 2014;146:974-81.

86 Stark H, Purokivi M, Kiviranta J, et al. Short-term and seasonal variations of exhaled and nasal NO in healthy subjects. Respir Med 2007;101:265-71.

87 Ekroos H, Karjalainen J, Sarna S, et al. Short-Term variability of exhaled nitric oxide in young male patients with mild asthma and in healthy subjects. Respir Med 2002;96:895-900.
88 Heaney LG, Busby J, Bradding P, et al. Remotely monitored therapy and nitric oxide suppression identifies nonadherence in severe asthma. Am J Respir Crit Care Med 2019;199:454-64.

89 Bronnimann S, Burrows B. A prospective study of the natural history of asthma. remission and relapse rates. Chest 1986;90:480-4.

90 Panhuysen $\mathrm{Cl}$, Vonk JM, Koëter $\mathrm{GH}$, et al. Adult patients may outgrow their asthma: a 25-year follow-up study. Am J Respir Crit Care Med 1997;155:1267-72.

91 Westerhof GA, Coumou H, de Nijs SB, et al. Clinical predictors of remission and persistence of adult-onset asthma. J Allergy Clin Immunol 2018;141:104-9.

92 Ross KR, Gupta R, DeBoer MD, et al. Severe asthma during childhood and adolescence: A longitudinal study. J Allergy Clin Immunol 2020;145:140-6.

93 Ayres JG, Miles JF, Barnes PJ. Brittle asthma. Thorax 1998;53:315-21.

94 Vahlkvist S, Sinding M, Skamstrup K, et al. Daily home measurements of exhaled nitric oxide in asthmatic children during natural birch pollen exposure. J Allergy Clin Immunol 2006;117:1272-6.

95 Skiepko R, Zietkowski Z, Tomasiak-Lozowska MM, et al. Bronchial hyperresponsiveness and airway inflammation in patients with seasonal allergic rhinitis. J Investig Allergol Clin Immunol 2011;21:532-9.

96 Selvanathan J, Aaron SD, Sykes JR, et al. Performance characteristics of spirometry with negative bronchodilator response and methacholine challenge testing and implications for asthma diagnosis. Chest 2020;158:479-90.

97 Richmond I, Booth $\mathrm{H}$, Ward C, et al. Intrasubject variability in airway inflammation in biopsies in mild to moderate stable asthma. Am J Respir Crit Care Med 1996:153:899-903.

98 Fleming L, Tsartsali L, Wilson N, et al. Sputum inflammatory phenotypes are not stable in children with asthma. Thorax 2012;67:675-81.

99 Silkoff PE, Laviolette M, Singh D, et al. Longitudinal stability of asthma characteristics and biomarkers from the airways disease Endotyping for personalized therapeutics (ADEPT) study. Respir Res 2016;17:43.

100 Kupczyk M, Dahlén B, Sterk PJ, et al. Stability of phenotypes defined by physiological variables and biomarkers in adults with asthma. Allergy 2014;69:1198-204.

101 Roenneberg T, Kuehnle T, Juda M, et al. Epidemiology of the human circadian clock. Sleep Med Rev 2007;11:429-38.

102 Horne JA, Ostberg O. A self-assessment questionnaire to determine morningnesseveningness in human circadian rhythms. Int J Chronobiol 1976:4:97-110.

103 Adan A, Archer SN, Hidalgo MP, et al. Circadian typology: a comprehensive review. Chronobiol Int 2012:29:1153-75.

104 Asthma UK. Digital asthma: re-imagining primary care. Available: https://www. asthma.org.uk/support-us/campaigns/publications/digital-asthma/ [Accessed 20 Nov 2020].

105 Martin JL, Hakim AD. Wrist actigraphy. Chest 2011;139:1514-27. 